\title{
EL DERECHO DE SUPERFICIE EN LA NUEVA LEY DEL SUELO
}

711.14:347.2

\author{
por \\ Felipe Díaz Capmany \\ Abogado
}

SUMARIO: I. PLANTEAMIENTO.-II. REGULACION ACTUAL DEL DERECHO DE SUPERFICIE, SEGUN LA NUEVA LEY DEL SUELO:

1. Normativa aplicable. 2. Constitución. 3. Contraprestación en el Caso de CONSTitución a tfrulo oneroso. 4. Circulación del derecho. 5. EXTINCIÓN. 6. BENEFICIOS.-III. ANALISIS DE LAS INNOVACIONES INTRODUCIDAS POR LA NUEVA LEY DEL SUELO.IV. CONSIDERACIONES SOBRE LAS POSIBILIDADES DEL DE. RECHO DE SUPERFICIE ATENDIENDO LOS SUPUESTOS DE QUE PARTE LA LEY DEL SUELO EN SU REGULACION.-V. EL DERECHO DE SUPERFICIE Y LA PROPIEDAD HORIZONTAL.VI. CONCLUSIONES GENERALES.-VII. PROPUESTA DE CLAU. SULAS CONTRACTUALES TIPO PARA LA CONCESION DEL DERECHO DE SUPERFICIE: 1. CANON DEL DERECHO DE SUPERFICIE. 2. OBRAS DE CONSERVACION Y MEJORA. 3. EXTINCIÓN DEL DEREC H O POR TRANSCURSO DE PLAZO. 4. CESIÓN DEL USO DE LAS CONSTRUCCIONES POR EL SUPERFICIARIO MEdIANTE PRECIO. 5. RESOLUCIÓN POR MODIFICACIÓN DEL PLANEAMIENTO.

\section{PLANTEAMiento}

La revitalización del derecho de superficie fue acogida como feliz iniciativa de la Ley del Suelo de 1956. En él el legislador puso esperanzas, y la doctrina calificó positivamente la reintroducción 
en el dęrecho vivo de aquella institución, para la cual el artículo 1.611 del Código civil, se dijo, casi fue un epitafio.

Múltiples han sido los objetivos que por el legislador o por la doctrina se han señalado al derecho de superficie. Entre ellos, el fomento de la construcción, la contención del alza de precios del suelo edificable, la retención de plusvalía por parte de la comunidad, la facilitación a largo plazo de las operaciones de renovación urbana.

Pese a esta amplitud de fines asignados a la figura rediviva, que reaparecía en la constelación jurídica como solución, alternativa o complementaria, a problemas muy agudos del urbanismo, y pese al aval prestado por el deslumbrante desarrollo de la institución en países extranjeros, los resultados prácticos, sin embargo, no respondieron a la confianza depositada. Pocas han sido - si alguna ha habido- las realizaciones desarrolladas en este campo.

La nueva Ley del Suelo, convencida todavía de la virtudes del derecho de superficie, pero ante la evidencia de que algo faltaba en su regulación que no la hacía atractiva en la doble vertiente de sus potenciales beneficiarios, ha insistido de nuevo en la institución, aunque otorgándole nuevos perfiles, seguramente para mejorar su imagen. No ha sido un simple retoque. Los artículos 157 a 161 de la Ley de 1956, reguladores del derecho de superficie, fueron objeto íntegramente de nueva redacción en la Ley 19/1975, de 2 de mayo, y esta nueva redacción ha pasado, con casi absoluta fidelidad, a los artículos 171 a 174 del Texto refundido, aprobado por Real Decreto 1.346/1976, de 9 de abril.

Los Municipios, inútil decirlo, son los protagonistas naturales del urbanismo. Del uso que hagan del derecho de superficie en sus actuaciones urbanísticas depende que esta institución alcance el nivel de aplicación que pretende suscitar la Ley. El objeto de este trabajo no es sino analizar someramente el nuevo derecho de superfice - porque nuevo es-, intentar precisar los obstáculos o los inconvenientes que la actual regulación comporta y definir qué áreas de actuación y qué modalidades pueden ser las más adecuadas para un óptimo desenvolvimiento de la institución en el nuevo marco.

El desarrollo de la exposición que a continuación se hace no alcanza un mínimo nivel sistemático. Un poco la forma en que este trabajo se gestó y un poco también el afán de plegarlo al máximo 
a la fuente legislativa, han dado lugar a este desarrollo fragmentario y reiterativo en algunos puntos. Tras una exposición sucinta del nuevo régimen, con apostillas ya sobre las innovaciones que el nuevo texto supone respecto del derogado, se sigue con un análisis conjunto de las novedades, contrastadas con las que el legislador confiesa en la exposición de motivos, para continuar con un capítulo relativo a consideraciones generales sobre las posibilidades que ofrece la institución al hilo también de la exposición de motivos de la Ley, y seguir luego con una cuestión, en cierta forma marginal, pero que se estima de importancia en la vida de la institución, cual es sus relaciones con el derecho de propiedad horizontal, terminándose con las conclusiones divididas en dos capítulos: conclusiones generales y conclusiones más concretas sobre los puntos que se consideran esenciales para la puesta en marcha de la institución, con propuesta de cláusulas tipo para la concesión del derecho con las que se pretende resolver o encauzar los problemas más agudos que la nueva regulación plantea.

\section{REGULACION ACTUAL DEL DERECHO DE SUPERFICIE SEGUN LA NUEVA LEY DEL SUELO}

\section{Normativa aplicable}

El derecho de superficie se regirá por las disposiciones contenidas en la Ley del Suelo, por el título constitutivo del derecho y, subsidiariamente, por las normas del Derecho privado (art. 171, 2).

El Código civil, en el artículo 1.611, se limita a mencionar, sin regular, el derecho de superficie. El artículo 1.655, precepto muy general, que se refiere a los foros y cualesquiera otros gravámenes de naturaleza análoga, entre los que puede encontrărse el derecho de superficie, remite, en su régimen, a las disposiciones reguladoras del censo enfitéutico, cuando sean por tiempo indefinido, cosa que no ocurre con el derecho de superficie, que por la Ley del Suelo es esencialmente temporal. Algún autor -GuILARTE - opina que, en la modalidad de canon periódico, cabría la aplicación de las normas del Código civil sobre arrendamiento. Las analogias de ambas figuras - derecho de superficie y arrendamiento de terreno con derecho a construir- son notorias; en Francia conviven las dos figuras (G. MARTY: "El derecho de superficie en relación con la planificación urbana», Revista de Derecho Urbanistico, 1972, núm. 27, pág. 29). 
La Ley Hipotecaria también se limita a mencionar el derecho de superficie (art. 107, 5). Y el Reglamento Hipotecario, en el artículo 16, hace una cierta regulación de fondo del derecho de superficie, pero sin dar mayor densidad a su ordenación en relación con la Ley del Suelo.

\section{Constitución}

1) Sujeto activo concedente. El Estado, las Entidades locales y urbanísticas especiales y las demás personas públicas dentro del ámbito de su competencia, así como los particulares en terrenos de su propiedad (art. 171, 1).

2) Sujeto pasivo titular del derecho. Superficiario (art. 171, 1).

3) Finalidad. La construcción de viviendas, servicios complementarios, instalaciones industriales $y$ comerciales $\mathrm{u}$ otras edificaciones determinadas en los Planes de ordenación (art. 171, 1).

La nueva Ley, en relación con la antigua, adiciona lo subrayado, aunque es una ampliación que estaba implícita en la expresión "otras edificaciones determinadas en los Planes de ordenación», a que se refería la Ley de 1956.

4) Procedimiento de constitución. En el caso de personas públicas:

A) Mediante subasta $(172,1)$.

B) Por adjudicación directa $(172,1)$. Gratuitamente o por precio inferior al coste, mediante autorización del Ministerio de la Gobernación, tratándose de Administración local $(172,1)$ y siempre que los terrenos sean destinados a:

- atender necesidades de viviendas de carácter social $(172,1)$;

- edificios públicos destinados a organismos oficiales $(172,1)$;

- edificios de servicio público, de propiedad pública o particular que requieran un emplazamiento determinado, sin propósito especulativo, como centros parroquiales, culturales, sanitarios o instalaciones deportivas $(172,1)$;

- construcción de viviendas por organismos oficiales $(172,1)$.

C) Mediante expropiación parcial del dominio del suelo, cuando así lo permita la ejecución del Plan $(172,1)$. (Modalidad nueva en relación con la vieja Ley). 
5) Formalización e inscripción. Deberá en todo caso ser formalizada la constitución en escritura pública y, como requisito constitutivo de su eficacia, inscribirse en el Registro de la Propiedad $(172,2)$.

\section{CONTRAPRESTACIÓN EN EL CASO DE CONSTITUCión}

\section{A TITULO ONEROSO}

Sin perjuicio de la reversión total de lo edificado al finalizar el plazo que se hubiese pactado, la contraprestación del superficiario podrá consistir en:

a) Pago de una suma alzada $(172,3)$.

b) Pago de un canon periódico $(172,3)$.

c) Adjudicación en viviendas o en locales o en derechos de arrendamiento $(172,3)$.

d) Varias de estas modalidades a la vez $(172,3)$.

La modalidad c) es nueva en la actual Ley, aunque una interpretación amplia de la vieja podía permitirla. Se suprime la modalidad prevista en la vieja Ley, artículo 158, 3, de que la contraprestación consistiese en la reversión gratuita de lo edificado.

\section{Circulación del derecho}

El derecho de superficie será transmisible y susceptible de gravamen, con las limitaciones que se hubieran fijado al constituirlo $(171,2)$.

En la vieja Ley -artículo 159, 3-, y salvo pacto en contrario, no se podía enajenar el derecho sin autorización del propietario del suelo, en tanto no hubiere edificado la mitad. También en la vieja Ley -artículo 160 - se establecían derechos de tanteo y retracto para la otra parte en caso de enajenación a título oneroso del terreno o del derecho de superficie. No parece que haya inconveniente que por convenio expreso se introduzcan estos derechos en el. título constitutivo. 


\section{ExTINCIÓN}

\section{1) Causas.}

A) Si no se edifica en el plazo previsto en el Plan o en el convenido si fuera menor $(173,1)$.

En la vieja Ley -ártículo $159,1-$, el plazo de construcción no se subordina al Plan, sino sólo al pacto, que no podía exceder de cinco años si el concedente era persona pública.

B) Transcurso del plazo que se hubiere pactado al constituirlo, que no podrá exceder de:

- Setenta y cinco años en el concedido por personas públicas $(173,1)$.

- Noventa y nueve años en el convenido entre particulares $(173,1)$.

En la vieja Ley -artículo 161-, el plazo de setenta y cinco-años era de cincuenta.

2) Efectos.

A) En cuanto a las construcciones. El dueño del suelo hará suya la propiedad de lo edificado, sin que deba satisfacer indemnización alguna cualquiera que sea el título en virtud del cual se hubiere constituido el derecho $(173,2)$.

Parece que no cabe pactar indemnización al término del derecho de superficie por razón de las construcciones existentes. Esta conclusión, no compartida por GoNZÁlez PéREZ (Comentarios a la Ley del Suelo, 1976, pág. 892), entendemos resulta de que en el orden de fuentes (art. 171, 2) aparecen, en primer lugar, las normas de la Ley del Suelo, y sólo en segundo término el título constitutivo. Confirmando la tesis, el artículo 173, 2, dice textualmente: «Sin que deba satisfacer indemnización alguna cualquiera que sea el título en virtud del cual se hubiese constituido aquel derecho", con lo que expresamente se subordina el título a la norma. Y el artículo 172, 3, al establecer las modalidades de contraprestación posible a satisfacer por el superficiario, añade al final: «Sin perjuicio de la reversión total de lo edificado al finalizar el plazo que se hubiera pactado al constituir el derecho de superficie»; es decir, que esta reversión total sin indemnización pasa a ser un plus a cualquier forma de prestación onerosa, que se establece de esta forma como esencial en la configuración del derecho. 
Argumento adicional es la comparación de los textos de la Ley del Suelo en su versión actual y en la redacción de 1956. En 1956, en el artículo 161,2, se preveía que, en defecto de pacto, el dueño del suelo debería satisfacer al superficiario una indemnización equivalente al valor de la construcción según el estado de la misma en el momento de la transmisión. El silencio absoluto, en la nueva Ley, acerca de una posibiidad de pacto en contrario, en relación con el régimen opuesto que se establece como norma general - no indemnización de construcciones-, parece envolver una proscripción total de la indemnización. También el artículo 158, 3, de la vieja Ley establecía, dentro de las modalidades de prestación en la constitución onerosa, y como una de ellas, la reversión gratuita de las edificaciones al dueño del suelo, mientras que en la nueva, en el precepto paralelo 172, 3, no sólo no se autoriza que tal reversión gratuita pueda ser la contraprestación, sino que incluso expresamente se dice que no puede serlo. También de la comparación de ambos textos puede observarse una matización sutil, pero importante, introducida por la nueva Ley. La vieja, en el artículo 157, 1, tras un precepto análogo al actual artículo 171,1 , terminaba diciendo que «el dominio de las cuales (de las edificaciones) corresponderá al superficiarion. Ahora se dice: acuyo derecho (el de construir) corresponderá al superficiarion. Se cambia el término «dominio» de las construcciones por aderechon a construir o derecho sobre las construcciones, al que no se califica de dominio, introduciendo con ello un cambio esencial -que debe entenderse intencionado- en la naturaleza jurídica del derecho de superficie. Si antes el superficiario era dómine de las construcciones, pertenecía a la lógica de la figura el que, salvo pacto en contrario, ese dominio no pudiese ser despojado sin indemnización. La vaga innovación a un simple aderecho» sin catalogarlo en ninguna de las categorías juridicas clásicas, permite la negación institucional e imperativa de la indemnización, sin atentar a la esencia del Derecho por excelencia, la propiedad. La supresión en la nueva Ley del inciso último del antiguo artículo 161, 3 ("pero si el superficiario tuviese derecho a indemnización, ésta quedará subrogada en los de garantía»), induce también a pensar que la vigente Ley del Suelo ha puesto término a esta clase de indemnizaciones, puesto que, si por pacto pueden generarse, era obvia la conveniencia de mantener el precepto.

La negación del derecho a indemnización parece, de otra parte, congruente con la finalidad del derecho de superficie. Objetivo no confesado por la Ley, pero sí latente en la común opinión es, a la vez que reservar las plusvalías del suelo a la comunidad, facilitar en el futuro las operaciones de renovación urbana. Estas se verían entorpecidas si al termino del plazo hubieran de abonarse indemnizaciones por las construcciones existentes. La Ley parece pretender que sin carga alguna vuelvan los terrenos a la Administración, para aplicarlos al interés público que al momento de la extinción sea prevalente, y esto sin cortapisas económicas de ningún género. La mayor objeción que pueda hacerse es haber establecido un régimen igual al derecho de superficie 
otorgado por los particulares, pues en este caso lo único que se protege y se potencia es la retención de plusvalías, indefinidamente, por los actuales propietarios del suelo.

CHICo ORTIZ ( $\mathrm{E}$ El derecho de propiedad ante la nueva legislación urbanística», Revista de Derecho Urbanistico, 1973, núm. 33, pág. 109) califica de expoliación la supresión de la indemnización que hacía el entonces proyecto de la Ley del Suelo, lo que induce a pensar que en su opinión era norma de derecho necesario.

B) En cuanto a los derechos reales y personales impuestos por el superficiario. En el caso de extinción por decurso del término, se extinguen asimismo todos estos derechos $(173,3)$.

C) Si se produce confusión de concedente y superficiario, salvo en el caso de extinción por decurso del plazo, las cargas que pesaren sobre los derechos de propiedad y sobre los derechos del su. perficiario continuarán gravándolos separadamente $(173,4)$.

\section{BENEPICIOS}

Los que se establezcan reglamentariamente respecto de la concesión de calificaciones, préstamos y ayudas previstas en la legislación protectora de viviendas (174).

\section{ANALISIS DE LAS INNOVACIONES INTRODUCIDAS POR LA NUEVA LEY DEL SUELO}

"Las novedades más importantes en esta materia -dice la exposición de motivos de la Ley del Suelo- consisten en la ampliación del objeto, de la finalidad, del plazo y de las modalidades de contraprestación. Con esas innovaciones y con el otorgamiento de determinados beneficios se aspira a crear los presupuestos económicos y jurídicos indispensables para que esta figura deje de ser una pura posibilidad legal y adquiera carta de naturaleza en la realidad urbanística española».

En el apartado anterior se han concretado las novedades de la nueva regulación en relación con la antigua, que coinciden con las señaladas por la exposición de motivos. Sin embargo, hay dos aspectos que silencia el preámbulo de la Ley. Uno fundamental: la no indemnización del valor de las construcciones. El silencio de la exposición de motivos sobre este punto, más importante que todos 
los demás, y que debiera haber mencionado incluso en el supuesto de que cupiese pacto en contra, produce la impresión de que no es grande la convicción del legislador sobre lo beneficioso de la novedad, que se abstiene de proclamar. No hay duda que constituye un importante estímulo para el ofrecimiento de suelo en estas condiciones; pero no cabe duda también que es un poderoso obstáculo para su aceptación por los usuarios.

Además, estrechamente relacionado con el problema de la indemnización en el momento de la reversión de las edificaciones, está el de la conservación de éstas. Escasas serán las obras de conservación, y menos las de mejora, que se realizarán en el edificio, especialmente en la última etapa de la vida del derecho de superficie, si no existe compensación. Se producirá un fenómeno de extremada depauperación, que convertirá las construcciones en inhabitables, en grado mayor al fenómeno análogo que se ha producido con las viviendas sometidas a la Ley de Arrendamientos urbanos.

Es curioso este cambio de rumbo de la Ley española, cuando en otras legislaciones, la francesa por ejemplo, la evolución ha sido la opuesta. Así, frente a la Ley de 1964, de arrendamiento para construcción, que no reconocía indemnización, salvo pacto, la de 1967, de concesiones inmobiliarias, establece con carácter obligado la indemnización, aunque con limitaciones. Y en 1972 existía una corriente de opinión en Francia (Informe BARTON) que no sabemos si ha cristalizado en norma, favorable a un mejoramiento de la indemnización, «con el fin de estimular la conservación de los inmuebles».

También se ha expuesto en el apartado anterior la sutil alteración del derecho del superficiario sobre las construcciones, que conscientemente se evita calificarlo de propiedad. El cambio puede tener repercusiones de alguna trascendencia en las relaciones del derecho de superficie con la propiedad horizontal.

La supresión de los derechos de tanteo y retracto, que se reconocían en el artículo 160 de la Ley del Suelo de 1956, tampoco merece un juicio positivo, aunque, como antes se ha dicho, entendemos pueden establecerse contractualmente. Tales derechos introducen una trasparencia deseable en el mercado de los derechos sobre el suelo y sobre las construcciones. Es indudable, sin embargo, que su supresión mejora la perspectiva de la institución, a los ojos de los interesados, al eliminar trabas a la libre circulación de los respectivos derechos. 
Las demás diferencias, de las confesadas en la exposición de motivos, salvo la ampliación del plazo, que es innovación importante y entendemos positiva, aunque no se comprende la razón de la duplicidad del límite temporal establecido, según se trate de personas públicas o particulares, tienen escasa trascendencia. En realidad, o estaban implícitas en la Ley anterior o podían desenvolverse dentro del ordenamiento jurídico a través de pacto.

\section{CONSIDERACIONES SOBRE LAS POSIBILIDADES DEL DERECHO DE SUPERFICIE ATENDIENDO LOS SUPUESTOS DE QUE PARTE LA LEY DEL SUELO EN SU REGULACION}

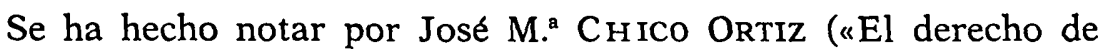
propiedad ante la nueva legislación urbanística», Revista de Derecho Urbanístico, 1973, núm. 33, pág. 97) que si el paso de la Edad Media a la Edad Moderna resolvió un problema político, apartando la soberanía de la propiedad, y un problema social, desplazando la propiedad al poseedor y procurando acabar con la distinción entre dominio directo y dominio útil, proceso que completó la Revolución francesa, en los momentos actuales estamos asistiendo a un fenómeno que se llama no de evolución, sino de "involución jurídica», al intentarse de nuevo escindir la propiedad - derecho de superficie, entre otros- y unirla a la soberanía - nacionalización, estatificación, socialización, etc., del suelo-. "Aquel tránsito de propiedades - añade- que supuso resolver la situación social hizo propietarios a los poseedores de los terrenos que son los que hoy día "especulan» con las posibles "plusvalías» que la transformación de los terrenos rústicos en urbanos plantea y que es uno de los más graves problemas que el urbanismo debe urgentemente resolver».

Parece interesante atisbar el derecho de superficie con esa perspectiva histórica, porque puede desvelar alguna de las claves del problema que plantea.

La exposición de motivos de la Ley vigente le dedica los siguientes párrafos al derecho de superficie:

El derecho de superficie como fórmula de disociación de la propiedad y uso del suelo es una figura que está mereciendo creciente atención en todos los países como instrumento de política del suelo. A cam- 
bio de una limitación temporal en el uso de los terrenos se obtienen éstos a un menor coste, con lo que se reduce el volumen inicial de recursos necesarios en el sector inmobiliario o en otras actividades productivas para atender a las necesidades de la demanda. Representa también un estímulo para la movilización del suelo por los propietarios privados, que pueden así poner en el mercado estos bienes a disposición de los promotores sin renunciar a su recuperación futura con la revalorización correspondiente. La promoción industrial y el fomento de las viviendas en alquiler pueden encontrar en el derecho de superficie un complemento de gran interés.

Desde la perspectiva de los patrimonios públicos de suelo, el derecho de superficie puede y debe ser un instrumento mediante el que, cada vez más, se procure que el derecho de propiedad sobre el suelo urbano, una vez que entre en la esfera patrimonial de la Administración, no salga de la titularidad pública; el incremento no sólo en el espacio, sino en el tiempo de los patrimonios públicos de suelo debe seguir siendo pieza clave de la política urbanística.

La exposición de motivos de la Ley del Suelo de 1956 era más parca en la presentación del derecho de superficie:

El fomento de la edificación no precisa, ni a veces aconseja, la enajenación de los terrenos: basta la constitución del derecho de superficie. La experiencia extranjera muestra las intensas posibilidades de esta figura jurídica que, a la vez que facilita la construcción, evita la especulación en edificios y terrenos y reserva el aumento de valor del suelo para el propietario. De aquí que se admita la constitución del derecho de superficie por Entidades públicas y por particulares.

De la exposición de motivos de la Ley vigente podemos destacar los siguientes perfiles de la institución, o mejor, los supuestos que han movido al legislador a institucionalizar el derecho de su. perficie, poniendo en él determinadas esperanzas.

\section{A) Es figura de disociación de la propiedad y uso del suelo.}

Afirmación cierta (1). Sin embargo, la corriente histórico-social, en la que todavía estamos inmersos, es opuesta a esta disociación,

(1) Existe otra disociación que se viene abriendo paso en las legislaciones occidentales, consistente en divorciar la propiedad del derecho de edificar. La exposición de motivos de nuestra Ley de 1975 bordea la cuestión cuando en su párra. fo $V$ dice que ula aptitud para edificar la da el Plan, pero el derecho a edificar se condiciona, con todas sus consecuencias, al efectivo cumplimiento de las obligaciones y cargas que se imponen al propietarion. En estas legislaciones a que nos referimos, no es que el derecho a edificar quede condicionado, sino que queda sustrafdo de la propiedad. Comenzo la Town and Country Planning Act, de 1947, 
como hemos visto en la opinión recogida más arriba. La realidad, de otra parte, lo acredita. «Pese a los años de vigencia de la Ley del Suelo -dice González PÉREz (Comentarios a la Ley del Suelo, página 897)—, los preceptos de la misma reguladores del derecho de superficie han quedado prácticamente inéditos. La reforma de 1975 ha intentado estimular su utilización. Pese a las modificaciones introducidas, no parece vaya a cambiar el panorama de nuestra realidad urbanística». ¿Por qué esta inaplicación de la figura?

Precisamente durante el tiempo de vigencia de la vieja Ley del Suelo (la Ley de Propiedad horizontal es de 21 de julio de 1960) ha irrumpido con fuerza la también llamada propiedad de casas por pisos. El dato es importante, porque, de hecho, la explosión urbanística de las grandes ciudades se ha producido con este instrumento jurídico, que no entró en el cálculo de la Ley del Suelo, la cual ponía su esperanza, para estimular la construcción, en el derecho de superficie («la experiencia extranjera muestra las intensas posibilidades de esta figura jurídica -exposición de motivos de la Ley del Suelo de 1956 - que, a la vez que facilita la construcción...»). No ha sido el derecho de superficie, sino la propiedad horizontal, lo que ha facilitado la construcción en España.

La realidad nos parece que acredita dos cosas. Que el derecho de superficie no interesa al propietario del terreno. $Y$ que tampoco interesa al presunto superficiario. En cuanto a este último, quizá la explicación haya de buscarse en las mismas causas, pero con signo opuesto, que han determinado el éxito de la propiedad horizontal. La propiedad horizontal no es cómoda, y para el usuario, desde luego, es mucho menos cómoda que el arrendamiento. Sin embargo, el arrendamiento se bate en franca retirada, mientras que la propiedad horizontal escala posiciones. Es indudable que en sectores sociales con amplias posibilidades económicas de elección, la propiedad horizontal ha tenido la misma penetración que en los sectores más modestos, para los que la propiedad horizontal podría suponerse como elección forzada. Y ello pese a un dato, de general conocimiento, de que los precios de las viviendas de lujo, en propiedad horizontal, excede la tasa razonable de capitalización de

en Inglaterra; le han seguido, parcialmente, la Ley francesa de 31 de diciembre de 1975, y últimamente, en Italia, la Ley de 28 de enero de 1977. El derecho a edificar según estas leyes -en Francia sólo respecto del exceso sobre un índice legalpertenece a la comunidad, que lo concede al propietario mediante el pago de un tributo. Inglaterra, en 1975, ha dado un nuevo paso: todo el suelo edificable debe ser adquirido por la comunidad. 
la renta de alquiler de viviendas análogas. No hay duda que existe un fenómeno psicológico, quizá enraizado en el carácter reverencial que sigue disfrutando el derecho de propiedad, tan trabajosamente conquistado por extensas capas sociales a lo largo de siglos y no ajeno al estado de seguridad que proporciona respecto de un elemento tan vital como la vivienda. Pero si se indaga bajo la superficie del fenómeno, descubriremos, en un estudio cronológico de valores inmobiliarios, que el factor psicológico tiene sólido fundamento en la realidad económica. La vivienda (generalizando en la vivienda lo que puede decirse igual respecto de valores análogos) se ha convertido en el único bien que, además de proporcionar un uso, a corto y medio plazo; y aun a largo plazo en la terminología usual (veinte años), no sólo no se deprecia, sino que se revaloriza aun por encima de los índices de inflación. Lo que pueda ocurrir a plazos más largos, más que no interesar, es absolutamente una incógnita, tanto en un estudio objetivo (la institución de la propiedad horizontal no ha contrastado enteramente sus defectos, pues no se ha llegado aún al momento de extinción de las situaciones que ha creado, momento que coincidirá con la ruina de las construcciones) como para el individuo, a quien escasamente afectan planteamientos que vislumbra vagamente para después de su vida y quien, en última instancia, razonablemente espera una intensa y póstuma revalorización de su porcentaje en la propiedad del suelo.

Otro aspecto económico subyace en el fenómeno. $\mathrm{Y}$ es el de que la adquisición de la vivienda en propiedad horizontal, aunque en algunos casos al límite de la capacidad económica del individuo, comporta la certeza de que nunca representará una carga superior al cálculo hecho, virtud derivada de la congelación total del precio y de las cargas financieras, mientras que en los regímenes imperantes de alquiler (en los sectores no protegidos) los pactos de revalorización, según el índice de precios, que han llegado a convertirse en cláusula de estilo para todos los contratos, introducen una azarosa incertidumbre en el cálculo de las posibilidades reales de afrontar las rentas en el futuro. Amenaza tanto más aguda atendidas las tasas de inflación en que la economía se mueve.

El derecho de superficie no otorga una propiedad. La nueva Ley del Suelo, especialmente, ha purgado escrupulosamente su texto de toda referencia al dominio o al derecho de propiedad para expresar la titularidad del superficiario. El actual artículo 171 ha suprimido la mención al dominio que contenía el paralelo artículo 157 de la 
Ley de 1956. El actual artículo 172, 2, hace referencia a la reversión total de lo edificado, mientras que el análogo artículo 158,3 , de la vieja Ley decía «reversión de la propiedad». Solamente el actual artículo 173, 2, utiliza la expresión "propiedad de lo edificado», pero para asignarla al dueño del solar cuando se extinga el derecho de superficie por el transcurso del plazo.

$\mathrm{Y}$ es que una propiedad a la que le falta la plenitud en el tiempo, la perpetuidad, pierde una nota esencial dentro de la concepción clásica del dominio, coincidente con una de las aspiraciones más caras al hombre, configurador de la institución a imagen de una apetencia codiciada: la permanencia en el tiempo. Se ha dicho que la propiedad es el derecho que puede serlo todo -incluso nada- Hay una referencia, en esta expresión, a las infinitas mutilaciones de que es susceptible la propiedad, sin dejar de ser propiedad (toda la serie de derechos reales y aun personales que no hacen sino sustraerle atribucjones). Lo que es más problemático es una limitación institucional a su dimensión temporal, al margen, claro está, de la facultad de disponer, por voluntad actual o diferida, simple o condicionada.

No siendo propiedad la del superficiario, falta ya, en principio, la nota esencial que ha hecho triunfar a la propiedad horizontal. Y no es sólo cuestión de imagen, más o menos deseable, sino que, frente a la progresiva e ilimitada revalorización de la propiedad horizontal, las construcciones al amparo del derecho de superficie nacen para ver decrecer su valor económico desde el primer día. No puede esperarse la inversión del ahorro más importante que para la generalidad de la población significa la adquisición de la vivienda, cuando la inversión es a fondo perdido.

Por el lado del propietario del suelo, la figura en principio parece que habría de ser atrayente. Su no uso puede tener la explicación de la falta de mercado real o supuesto por las razones antes expuestas. Pero quizá esté latente también una desconfianza en la misma legislación que regula el derecho de superficie. Es todavía reciente, especialmente en Cataluña, y en Barcelona en particular, lo que pasó con institución tan análoga como la enfiteusis. Se dijo por Pella, en frase repetida en los libros de texto, que Barcelona debe su crecimiento, indiscutiblemente, a la enfiteusis. Pero con la enfiteusis pasaron dos cosas que, sin duda, la hicieron caer en desuso. Primero, el censo se convirtió, como consecuencia de la progresiva e incontenible desvalorización de la moneda, en un puro 
símbolo, aunque el remedio hoy día podría encontrarse en las cláusulas estabilizadoras. En segundo lugar, y nos parece que fue golpe mortal, se estableció la redención obligada, impuesta en 1945, contradiciendo lo que le era esencial, la perpetuidad. Nada asegura que, dentro de unos años, lo que se consideró conveniente para la enfiteusis, la unificación del dominio dividido, no se considere también conveniente para el derecho de superficie.

B) Es figura que está mereciendo creciente atención en todos los paises como instrumento de politica del suelo.

También es esto cierto. Pero conviene no olvidar en qué circunstancias.

De Redéfinir le droit de propriété (J. P. GILLI) tomamos los siguientes datos.

La institución es particularmente utilizada en Holanda, países nórdicos, Gran Bretaña y Japón.

En Amsterdam, el Municipio utiliza desde 1896 el sistema de arrendamiento de setenta y cinco años, renovables por períodos de cincuenta años. El canon representa del 4 al 5 por 100 del precio de los terrenos. La municipalidad puede poner fin al arrendamiento, mediante un preaviso de cuatro años, para aplicar el bien a otro destino. El arrendatario es entonces indemnizado. El Municipio posee hoy 3.400 hectáreas.

En Estocolmo, las adquisiciones comenzaron en 1904. Hoy el Municipio posee 50.000 hectáreas, alrededor del 70 por 100 del territorio municipal. Los terrenos son alquilados por sesenta años, con reconducción posible por cuarenta años, salvo que la municipalidad quiera alterar el destino del suelo, con indemnización al arrendatario. Los demás países escandinavos, incluida Finlandia, han acudido a la misma práctica.

En Gran Bretaña, el régimen de arrendamiento de larga duración (noventa y nueve años) está muy extendido. Es particularmente utilizado por las autoridades municipales, que poseen actualmente cerca de 200.000 hectáreas.

En Japón es utilizado el mismo procédimiento. Los diques construidos para el nuevo puerto de Kobé (más de 1.000 hectáreas) han sido en parte concedidos por el Municipio por una duración de cincuenta años.

De estos muy breves datos podemos extraer las siguientes deducciones que pueden ser significativas. Primero, que se trata de 
países muy en la esfera de influencia, al menos durante bastante tiempo, de Inglaterra. En segundo lugar, que se ha tratado de actuaciones, por lo que reflejan las cifras, de carácter masivo. En tercer lugar, que la influencia socialista, manifestada no sólo en éste, sino en otros sectores ciudadanos, ha sido importante en la mayoría de estos países. En cuarto lugar, que falta una experiencia completa en cuanto al ciclo entero de la fórmula. Y quinto, que en cuanto al caso del Japón, se aporta un ejemplo de naturaleza industrial.

La primera deducción induce a pensar en unas circunstancias sociojurídicas que pueden no ser iguales a las de otros países pertenecientes a otras áreas de influencia. En este aspecto tiene interés lo que GuIlaRTe (El derecho de superficie, 1966) dice del caso in'glés: "También en Inglaterra, seguramente por influencia de la $B O$ denlehie alemana, se ofrecen un conjunto de contratos superficiarios que se agrupan bajo la denominación común de building-lease. La institución, creada por la práctica, según BALBI se extiende hasta la época contemporánea. Realmente es interesante destacar, como observa PLANITZ - continúa-, que el Derecho inglés une bajo el concepto lease todas las formas de censos inmobiliarios de fincas, desempeñando este concepto en Inglaterra el papel de arrendamiento de uso, de arrendamiento de uso y disfrute y también de derecho de superficie. Como en Londres mismo la tierra y el suelo se encuentra en propiedad de unos pocos magnates, la mayor parte de las casas están construidas sobre terreno de unas building-lease. El lease-holder tiene un derecho real, que es eficaz contra todo tercero; incluso contra el nuevo adquirente. El derecho es temporalmente limitado, casi siempre a ochenta o noventa años. Después del transcurso de los plazos en cuestión, la finca, con todas las construcciones, revierte al propietario (lanlord)». En el seno de "esta estructura jurídico-social no habría de haber inconvenientes para que las actuaciones municipales se adaptasen perfectamente a los imperativos de la New Town Act de 1946, que les obligaba a la conservación de la propiedad de los terrenos adquiridos y que eran cedidos a los constructores bajo la modalidad de arrendamiento enfitéutico (2). No hace falta subrayar que la estructura jurídico-

(2) El Libro Blanco sobre urbanismo de 1974, que plasmó la Community Land Act, va más lejos. Consecuencia del principio de que el suelo edificable debe ser adquirido por la comunidad, no se permite la construcción de ningún edificio, excepto en suelo perteneciente a la autoridad pública o cedido por dicha autoridad. 
social española ha sido exactamente la contraria a partir del Código civil, que se impuso como meta liquidar los censos enfitéuticos, pero no con reversión al dueño directo, sino con redención en beneficio del dueño útil.

La segunda deducción, la actuación masiva en cuanto a la adquisición de terrenos, que revelan las cifras de hectáreas aplicadas, un dato complementario, aunque muy fragmentario, la apoya: las subvenciones concedidas por el Estado a las municipalidades con tal finalidad alcanzaron en Inglaterra en 1964 los 164 millones de libras. Estas actuaciones masivas pueden dominar el mercado, imponiendo, guste o no guste, sus condiciones.

No debe insistirse en la influencia que haya podido tener en la expansión de la figura la tendencia socialista general en estos países, pues no cabe duda que los hábitos, las aspiraciones y aun los gustos pueden cambiar a tenor de la atmósfera imperante. La vivienda no deja de ser un bien, como tantos otros pendiente de las concepciones sociales en uso.

La cuarta conclusión: la falta de experiencia completa por, lógicamente, no haber vencido los largos plazos de duración de estos derechos, impide formular juicios definitivos. No faltan, sin embargo ya, algunas señales de alerta. Uno de los objetivos del derecho de superficie es el de facilitar las operaciones de renovación urbana. Pues bien (se toma el dato de la mencionada obra Redefinir le droit de propriété, pág. 52), en Suecia y en Holanda la práctica muestra un fortalecimiento de los derechos de los ocupantes análogo al que se constata en la URSS. Observación de extremado valor y que parece confirmar una inevitable pendiente hacia el poseedor sobre la que ruedan los derechos no plenos en busca de consolidación. El catedrático de Derecho civil SERRANo SERRANo, en el prólogo al libro de GuILARTe, tras afirmar que el momento de la extinción por el transcurso del tiempo constituye un verdadero escollo en la institución, hace las siguientes observaciones: «Mas estos problemas nos hacen pensar que este derecho de superficie pueda correr la misma suerte que nuestras viejas cargas censales, que, siendo inicialmente temporales, las cuestiones de orden público que se plantearon cuando quisieron los propietarios hacer efectiva su extinción por el transcurso del tiempo, dieron lugar a sucesivas prórrogas hasta convertirse en derechos perpetuos». Con su agudeza característica, el profesor Alfonso DE Cossfo, exponiendo al XVIII Congreso de la Propiedad Urbana de Sevilla, en el año 
1964, su ponencia sobre derecho de superficie, decía que cuando transcurrieran cincuenta años se celebraría un Congreso de superficiarios que reclamarían del Poder público la prórroga de sus derechos.

Por último, el caso del Japón tiene simple valor recordatorio de que el leasing donde se mueve con holgura es en el terreno empresarial, lo cual conviene tenerlo siempre presente.

Angel MARTfN DfEz-QuiJADA, en "La cesión de solares por la Administración en régimen de derecho superficiario" (Revista de Administración Pública, 1974, núm. 75) suministra los siguientes datos complementarios a los antes expuestos, que conviene retener. En Suecia, el canon equivale a un porcentaje de la renta que se pagaría por la vivienda edificada, situado entre un 6 y un 8 por 100 del alquiler tasado; el suelo es adjudicado a compañías inmobiliarias. En Gran Bretaña, el suelo adquirido por las Corporaciones locales es construido directamente, con cesión de las viviendas en alquiler, o bien es cedido en régimen superficiario; la cuantía del canon superficiario está sometida a revisiones periódicas, acomodando la cuantía a los ingresos percibidos por el superficiario. En Austria, el Ayuntamiento de Viena, al término de la primera guerra mundial, concedió a diversas sociedades inmobiliarias el derecho de superficie sobre amplias áreas del terreno del patrimonio municipal. En Estados Unidos existe una práctica constante que estriba en no enajenar el terreno patrimonial de las Corporaciones locales ni ceder el derecho de superficie por plazo superior a noventa y nueve años; se recomienda en informes oficiales, en interés de una buena administración, la concesión de terreno para edificios comerciales e industriales en las áreas centrales de las ciudades, en forma de ground leases, por plazo de setenta y cinco años.

Para terminar con esta ligera ojeada al extranjero, veamos someramente el caso de Francia e Italia. En la actualidad tiene Francia no una fórmula, sino dos, aparte de la enfiteusis, que, proscrita por el Código napoleónico, ha pervivido en los usos contractuales confirmados por los tribunales. La primera fórmula es el arrendamiento para construcción sancionado por Ley de 1964. La segunda fórmula es la concesión inmobiliaria regulada por Ley de 1967. Una exposición detallada de ambos sistemas se recoge en el trabajo de G. MARTY, «El derecho de superficie en relación con la planificación urbana» (Revista de Derecho Urbanistico, 1972, núm. 27). Destaquemos sólo que en la primera figura no hay indemnización final por 
las construcciones, salvo pacto. En la segunda, sí. De otra parte, la Ley de 30 de junio de 1972 prevé la posible prohibición a las Corporaciones públicas de enajenar la plena propiedad del suelo, así como limita las concesiones temporales al plazo máximo de setenta años, sin posibilidad para el concesionario de derecho ninguno de renovación o de mantenerse en la ocupación a la expiración del término. La Ley de 31 de diciembre de 1975 sobre reforma de la política del suelo autoriza concesiones de hasta noventa y nueve años. Es el propio MARTY el que en el artículo citado se muestra pesimista en cuanto al éxito de estas fórmulas. Termina diciendo que estos sistemas no tendrán aplicación general más que en la medida en que las Corporaciones públicas que dispongan de terrenos para edificar lleguen a imponer de hecho su uso.

En fin, en Italia, la Ley 865, de $22^{\circ}$ de octubre de 1971, modificando el artículo 10 de la Ley 167, de 18 de abril de 1962 sobre planes de zona para edificaciones económicas y populares, dispone en su artículo 35 que las áreas expropiadas serán cedidas en régimen de derecho de superficie en un 60 por 100 por una duración no inferior a sesenta años ni superior a noventa y nueve, mediante convenio que deberá regular, entre otros extremos, el canon de la concesión en cuantía igual al coste de la adquisición de las áreas, así como de las obras de urbanización si ya han sido realizadas; los criterios para la determinación y la revisión periódica de las rentas, así como para la determinación del precio de cesión de las viviendas donde ésta sea permitida, y los criterios para determinar el canon en caso de renovación de la concesión, cuya duración no podrá ser superior a la prevista en un principio.

También en Italia la opinión es un tanto escéptica. Así, Giancarlo MENGOLI ("Instituciones antiguas y nuevas. Programación de la edificación residencial», Revista de Derecho Urbanístico, 1972, número 29): «Está claro - dice- que sin una contribución masiva del sector público nadie querrá "construirse su casa" sobre estas ideas; solamente lo hará si va a costarle menos que a los demás y, muy especialmente, si no debe desembolsar un pago inicial, sino que todos los pagos sean iguales, a modo de plazos de un préstamo; de aquí la necesidad de financiar total o casi totalmente la obra».

C) Representa también un estímulo para la movilización del suelo por los propietarios privados, que pueden asi poner en el mercado estos bienes a disposición de los promotores sin renun- 
ciar a su recuperación futura con la revalorización correspondiente.

Es cierto el estímulo. Ahora bien, ni la Ley debería estimular con el acicate de las plusvalías (con las que, de otra parte, pretende acabar), ni es posible que du estímulo situado a tan largo plazo sea suficiente para inhibir el estímulo mucho más agudo de conseguir la plusvalía en el momento más adecuado mediante la simple retención de los terrenos. De otra parte, el derecho de superficie ofrece para el propietario la incertidumbre de un futuro demasiado lejano.

D) La promoción industrial y el fomento de la vivienda en alquiler pueden encontrar en el derecho de superficie un complemento de gran interés.

Debe considerarse cierta la afirmación, no tanto en relación con el propietario individual por las razones antedichas, cuanto para los patrimonios públicos de suelo y para el régimen de explotación empresarial.

E) Desde la perspectiva de los patrimonios públicos del suelo, el derecho de superficie puede $y$ debe ser un instrumento mediante el que, cada vez más, se procure que el derecho de propiedad sobre el suelo urbano, una vez que entre en la esfera patrimonial de la Administración, no salga de la titularidad pública; el incremento no sólo en el espacio, sino en el tiempo de los patrimonios públicos de suelo debe seguir siendo pieza clave de la política urbanistica.

Es el simple reflejo de una aspiración, para cuya plasmación ni la Ley prevé medidas coercitivas, como en Francia o Italia, ni ha facilitado los medios económicos necesarios.

\section{EL DERECHO DE SUPERFICIE Y LA PROPIEDAD HORIZONTAL}

Se ha indicado en apartados anteriores que la Ley ha hecho un intencionado esfuerzo para eliminar cualquier referencia a la propiedad cuando califica el derecho del superficiario sobre las construcciones. Determinar qué derecho ejerce el superficiario sobre las construcciones obligaría a ahondar mucho sobre el tema y con escasas posibilidades de éxito, pues la diversidad doctrinal es abrumadora. La figura con la que presenta mayores analogías 
es la del usufructo. Cumple todas y cada una de las notas que según CASTÁN caracterizan el usufructo. 1..$^{\circ}$ Ser un derecho real de disfrute o goce $\mathrm{y}$, por ende, de los llamados materiales, no formal o de garantía. $2 .^{\circ}$ Ser un derecho real mobiliario o inmobiliario. 3. Ser un derecho real temporal. 4. ${ }^{\circ}$ Ser actualmente un derecho transmisible. Además, según el artículo 487 del Código civil, las mejoras útiles o de recreo no son indemnizadas al término del usufructo, y los gastos de entretenimiento deben considerarse incluidos en el deber de conservación que al usufructuario incumbe con arreglo al artículo 467 del Código civil (3).

Ahora bien, en todo caso, lo que parece cierto es que no es un derecho de propiedad, salvo que lo incluyamos en el grupo heterogéneo de propiedades especiales. Siendo esto así, parece que no casa con la institución de la propiedad horizontal, que es, aunque complejo, verdadero dominio. El artículo 396 del Código civil, según la redacción de la Ley de 21 de julio de 1960, al definir la propiedad horizontal, la califica de derecho de propiedad en cuanto a las piezas separadas, y de copropiedad, en cuanto a los elementos generales, entre los que se incluye el suelo.

Si no puede haber copropiedad sobre el suelo, porque claramente el derecho no es de propiedad, sino de superficie, y tampoco existe propiedad sobre las piezas individuales de la construcción, parece difícil encajar una propiedad horizontal sobre la institución del derecho de superficie (4).

Sin embargo, no repugna, independientemente de la dicción de la Ley, el nacimiento de relaciones análogas a la propiedad horizontal sobre la base del derecho de superficie. Es más, la nueva Ley del Suelo lo da por supuesto cuando, en el artículo 172, 3, al enumerar las contraprestacionesaprevisibles, cita entre ellas la adjudicación en viviendas o en locales, lo que necesariamente llevará consigo un régimen de propiedad horizontal para el funcionamiento de la comunidad que por este camino habrá de surgir.

Sería deseable, no obstante, que en la reglamentación de la Ley del Suelo a que tan repetidamente remiten muchos de sus artículos,

(3) En Austria, la Ley de 26 de abril de 1912 dispuso la aplicación subsidiaria al derecho de superficie de las normas relativas al usufructo, según indica DE LOS Mozos (El derecho de superficie en general y en relación con la planificación urba. nistica, Ministerio de la Vivienda, Servicio Central de Publicaciones, Madrid, 1974).

(4) DE LOS MOZos, en la obra citada en la nota anterior, página 272, pone de relieve las dificultades de aplicación de la propiedad horizontal sobre el derecho de superficie y explica las soluciones que han sido adoptadas por el Derecho alemán. 
se estableciese el enlace preciso entre derecho de superficie y propiedad horizontal, especialmente necesario a efectos del Reglamento Hipotecario, con el fin de evitar dificultades a la hora de inscribirse los derechos en el Registro de la Propiedad.

\section{CONCLUSIONES GENERALES}

Podemos extraer de las anteriores reflexiones las conclusiones siguientes:

1. El derecho de superficie no es una figura enteramente experimentada, ni siquiera en los países que han sido pioneros en su aplicación al urbanismo. En la práctica se observa un endurecimiento de la institución al finalizar el ciclo, de forma que las previsiones de una recuperación fácil de los terrenos al término del plazo empiezan a no ser confirmadas por la realidad. El desalojo de los ocupantes de las construcciones al finalizar el ciclo puede suponer una carga económica importante que haga prohibitiva la operación. Sabido es que en muchos casos en el coste de expropiación de fincas alcanza mayor suma las indemnizaciones a los ocupantes que el justiprecio correspondiente al propietario. Pese a que el artículo 173, 3, de la Ley del Suelo dice que "la extinción del derecho de superficie por decurso del término provocará la de toda clase de derechos reales o personales impuestos por el superficiario", cuando tal ocurra, la presión social puede obligar al cambio de la norma, supuesto que subsista dentro de setenta y cinco años. En consecuencia, ni teóricamente puede aceptarse, sin temor a duda, que la fórmula sea conveniente, caso de ser posible.

Por consiguiente, la aplicación de una política municipal de utilización del derecho de superficie con el objetivo único de despejar, para el lejano mañana, todos los problemas económicos de las operaciones de renovación urbana, no tendría un fundamento al margen de avatares imprevisibles. Sin embargo, lo que al menos parece cierto, en el peor de los casos, es que los costes de renovación serían comparativamente menores, pues, aun suponiendo que hubiese que indemnizar a los ocupantes a través de un procedimiento igual o similar al de la expropiación, se evitaría siempre el pago de elevados justiprecios del suelo.

Las operaciones de renovación urbana comportan los siguientes sacrificios a cargo de una u otra economía: habilitación de nue- 
vo suelo edificable, construcción de las nuevas edificaciones, derribo de las antiguas, gastos de traslado de los ocupantes, sacrificio del viejo suelo. En una economía en que las plusvalías reales (las monetarias no son plusvalías) pertenecen al dueño del suelo, el beneficio que a la comunidad comporta la propiedad del terreno como patrimonio público se constriñe exactamente a la partida de «sacrificio del viejo suelo", que no deberá ser adquirido al valor venal. Habrá, pues, una economía consistente en la diferencia entre el valor teórico de mercado y el valor contable en patrimonio. Es.te valor contable en patrimonio se recuperará luego, en la medida en que el viejo suelo no se destine a dominio público.

En definitiva, se habrá conseguido uno de los objetivos asignados al derecho de superficie: la retención de plusvalías por el ente público, siendo efecto de segundo grado el abaratamiento de vivienda e instalaciones en el caso de que la plusvalía no sea explotada por la propia comunidad, lo que no depende sólo de su voluntad, sino de que el patrimonio público del suelo tenga envergadura suficiente para influir decisivamente los precios de mercado, pues debe rechazarse de raíz la creáción de un mercado inmobiliario artificial montado sobre el derecho de superficie, paralelo y sin relación de equivalencia económica con el tradicional fundado en la propiedad.

2." Los países en los que más se ha desarrollado la institución pertenecen a áreas en que los sistemas jurídicos y su evolución histórica no sólo es distinta, sino incluso contraria a nuestro país. En países de mayor analogía, como Francia, la fórmula no termina por ser socialmente aceptada. Concretamente en España, la realidad ha acreditado la no aceptación social de la institución por causas sobre las que se pueden hacer conjeturas, pero no sólidas afirmaciones. Entre ellas, el desinterés por una fórmula que no otorga la propiedad. Mientras subsista la avidez actual por la propiedad es difícil que cristalice en la práctica el derecho de superficie. Y la avidez por la propiedad no sólo es factor psicológico, sino que tiene razonables fundamentos económicos. Parece, pues, que la institución no puede fructificar dentro del campo de la propiedad horizontal, salvo en condiciones extremadamente beneficiosas.

Estas condiciones beneficiosas pueden buscarse en una doble dirección. De un lado, a través de una sustancial reducción del precio. De otro, mediante el reconocimiento al superficiario de ciertos 
derechos al término de la concesión. La primera dirección tiene un campo de movimiento limitado rígidamente por los condicionantes económicos y sociales. Como resulta de otra conclusión, el canon superficiario tiene que asegurar, al menos en el primer ciclo, una normal rentabilidad a las inversiones realizadas por el ente público para la adquisición del suelo.

En cuanto al reconocimiento al superficiario de ciertos derechos al término de la concesión, cabe, a su vez, una doble dirección: reconocer en el título constitutivo un derecho a la prórroga de la situación en determinadas circunstancias y reconocer, además o alternativamente, derechos indemnizatorios por el valor de las construcciones, el inicial o el añadido, dentro de determinados límites. Ni uno ni otro pacto, empero, parece que encajen dentro de la nueva normativa. Y éste es uno de los puntos en que la nueva Ley se hace acreedora de crítica, pues solícita a los intereses del oferente ha postergado hasta tal punto los del usuario, que puede hacer inviable la institución por ausencia de demanda, al menos en el terreno de la propiedad horizontal. Sin embargo, una interpretación de la nueva Ley, adaptada a las necesidades y ante la no prohibición, manifiesta y expresa, de pactos en contrario, puede admitir convenciones de esta índole que no atenten a la naturaleza misma del derecho de superficie, en la nueva configuración legal, ni a los intereses públicos.

La prórroga de la situación fáctica dentro de la misma u otra figura jurídica no repugna a la institución, puesto que si las construcciones permanecen en buen estado y no existe interés público en el cambio de destino, la situación habrá de continuarse con los mismos $\mathrm{u}$ otros usuarios. La indemnización al término del período por el valor residual de las inversiones realizadas tampoco pugna con la institución, antes al contrario estimula su fin esencial, pues nada más contrario a la misma que la progresiva depauperación de las construcciones que indefectiblemente se producirá en otro caso.

Tanto la posible prórroga como la indemnización acercarán la figura si no a la imagen del dominio, sí a sus efectos.

3. Más propicio se muestra al derecho de superficie el campo del arrendamiento y el uso industrial. Los inconvenientes que se conjeturan en relación con la vivienda como perteneciente a una unidad económica de consumo, no existen para una unidad económica de producción. La empresa, ya se dedique a la explotación de 
viviendas en alquiler, ya a actividades industriales, puede hacer, y de hecho hace, unos cálculos de rentabilidad entre cuyos factores incluye la amortización de las instalaciones. La pérdida final de las construcciones está en la misma naturaleza de su forma de funcionar. En estas dos modalidades es donde cabe esperar mayores posibilidades de expansión del derecho de superficie. Parece, pues, aconsejable, en cuanto a las viviendas, la intermediación de concesionarios, rígidamente controlados, que harán las veces de administradores no del patrimonio público, pero sí de las construcciones sobre él elevadas, en forma tal para la que, seguramente, ni el individuo consumidor está preparado ni tampoco lo esté la Administración.

Vale la pena, en este apartado, hacer alguna reflexión sobre un punto que nos parece conveniente destacar. El derecho de superficie, aplicado tanto a vivienda como a instalaciones, especialmente en la forma en que es estructurado en la nueva Ley, en que parece exigirse una total amortización de las construcciones al término del plazo, es un régimen económicamente caro, aunque pueda existir una compensación de tipo social. Nos parece que se inserta de lleno en la peyorativamente llamada sociedad de consumo. Las construcciones son para ser consumidas en el plazo máximo de setenta y cinco años, si el dueño del suelo es persona pública, y en el plazo máximo de noventa y nueve años, si el dueño del suelo es persona privada (en la diversidad de plazo hay un elemento discriminador que si la corriente social fuese favorable a la institución dejaría fuera de mercado a la Administración, cosa quizá no observada por el legislador). Y la sociedad de consumo es una sociedad cara. Nada se aprovecha hasta el final. Todo se sustituye al cabo de un plazo, no coincidente en general con el de la máxima utilidad posible. El bienestar social, singularmente en bien tan esencial como la vivienda, es el anverso de la medalla. Lo que está por ver es que el país sea económicamente capaz de renovar de raíz cada setenta y cinco años su patrimonio inmobiliario.

4. ${ }^{\mathrm{a}}$ Las actuaciones deben ser masivas y continuadas dentro de las posibilidades. Deben plantearse no como medida accidental, sino como política permanente. Deben además concentrarse en zonas determinadas.

Que las actuaciones tienen que ser de gran alcance viene determinado por las finalidades señaladas al derecho de superficie. Si, 
como se decía al principio, eran objetivos de la institución el fomento de la construcción, la contención del precio del suelo edificable y la retención de plusvalías por la comunidad, bien claramente se ve que ninguno de estos objetivos podrá ser cubierto con acciones aisladas que podrán servir de ensayo de la institución, pero que ningún efecto sensible tendrán ni en el volumen de construcción, ni en los precios del suelo, ni en la evasión general de las plusvalías hacia el sector privado. Otra razón existe en pro de las actuaciones de gran amplitud. La institución que, en principio y como se ha repetido, no es atrayente, sólo puede cobrar vigencia en la medida que se imponga, si no como solución única, sí como alternativa que cubra un amplio sector de la oferta total de viviendas o instalaciones industriales y comerciales.

La conveniencia de que las acciones se concentren en zonas determinadas resulta de otra de las finalidades asignadas al derecho de superficie: facilitar operaciones de renovación urbana, finalidad tanto menos alcanzable cuanto que la titularidad del suelo se desperdigue a lo largo y ancho del territorio municipal.

5. Para que las actuaciones sean masivas es preciso contar con unos medios financieros, desde luego muy superiores a las actuales disponibilidades de las Corporaciones locales. La índole de las operaciones, con efectos a largo plazo, aconseja la financiación a través de créditos también a muy largo plazo, con la garantía de los propios bienes y de sus rendimientos.

Otra alternativa, que nos parece en líneas generales excluyente de la anterior, es la que la Ley ofrece, en el artículo 172, 1, de constituir el derecho de superficie mediante expropiación parcial del dominio del suelo, quedando el propietario primitivo como titular del derecho de superficie, lo que, además del objetivo principal de conseguir con ello disminuir la masa de capital de maniobra necesario, simplifica el procedimiento, al dejar ya configurada la situación jurídica en el momento de la expropiación y compeler inexorablemente al antiguo propietario a construir no sólo por ser carga específica del derecho de superficie garantizada con la extinción del derecho, sino porque el valor de este derecho decrecerá paulatina pero progresivamente cada año.

En estos casos, el valor de la expropiación habría de reducirse al valor actual de la renta anual del suelo durante el período por el que se constituyere el derecho. Si se aplicase la valoración pre- 
vista a efectos del arbitrio de plusvalía en el artículo 92, 9, del Real Decreto $3.250 / 1976$, de 30 de noviembre, el valor sería igual al 30 por 100. En todo caso, las posibilidades de actuación quedarían multiplicadas.

La fórmula, sin embargo, envuelve problemas importantes de ejecución, ya que nos parece no existen antecedentes de expropiaciones de esta índole compleja, en las que no sólo se trata de sustraer un bien de la propiedad privada, sino de la imposición simultánea a título singular de obligaciones complementarias. También en este punto serían deseables especificaciones reglamentarias.

Se ha denunciado antes la incompatibilidad de este sistema con el de financiación por crédito de las expropiaciones. La razón está en que en estos casos no habría cobertura económica ni siquiera para el pago de los intereses, pues, como es natural, no mediaría canon anual, precisamente convertido en la reducción del precio de la expropiación.

6. Cuestión delicada es la determinación del canon del derecho de superficie. En todo caso, parece que no habría de ser simbólico, pues entonces las posibilidades de actuación quedarían extraordinariamente mermadas.

Antes se ha hablado de la conveniencia de operaciones de envergadura y continuadas, para las que necesariamente se habrá de contar con el crédito público o privado. En estos términos, la concesión del derecho de superficie con cánones simbólicos incapacitaría incluso para el pago de los intereses de los créditos, salvo la obtención de elevadas subvenciones a fondo perdido procedentes del Estado.

Moviéndose la actuación en una economía de mercado, el canon no puede ser inferior al tipo de interés de los créditos mediante los cuales se financien las operaciones. $Y$ para dar uniformidad a la gestión y evitar diferencias coyunturales que benefician a unos y perjudican a otros, alterando la normalidad del mercado, deberían establecerse escalas móviles, tanto en alza como en baja, que repartan equitativamente toda la carga financiera en curso.

De otra parte, el valor de los terrenos, para determinar la base del canon, habría de ser objeto de revalorizaciones periódicas - hay precedentes en el extranjero- que no sólo recojan las diferencias monetarias nominales, sino incluso las plusvalías reales originadas 
por la comunidad. Este capítulo podría constituir un poderoso medio para atender las amortizaciones de capital y proporcionar medios complementarios para futuras actuaciones.

No obstante, la fijación de un canon variable, tanto en cuanto al tipo como en cuanto a la base, introduce un elemento de incertidumbre que puede retraer la demanda, como antes se ha mencionado. Debe, no obstante, insistirse en su conveniencia, atendido especialmente el extensísimo plazo de duración del derecho de superficie que imposibilita cualquier previsión sobre la futura evolución de las condiciones económicas que determinaron sus pactos, evolución que habrá de tornar en injustas, para una u otra de las partes, sus recíprocas prestaciones si sus valores económicos quedan congelados al momento en que se establecieron.

\section{PROPUEȘTA DE CLAUSULAS CONTRACTUALES TIPO PARA LA CONCESION DEL DERECHO DE SUPERFICIE}

\section{CANON DEL DERECHO DE SUPERFICIE}

$\mathrm{Su}$ determinación tiene un significado eminentemente político. Los sistemas extranjeros antes mencionados muestran tres fórmulas. La fijación de un porcentaje fijo del valor del terreno (del 4 al 5 por 100 en Amsterdam). La fijación de un porcentaje, del 6 al 8 por 100 , del alquiler tasado de las viviendas, en Suecia. La fijación en función de los ingresos percibidos por el superficiario. Desechado este último sistema ante la dificultad en nuestro país de disponer de datos absolutamente veraces sobre las economías particulares, y el de Suecia, ante la inexistencia de una tasa general de alquileres, parece que no cabe sino acudir al sistema del porcentaje del valor del suelo. De otra parte, y según antes se ha expuesto, conviene, especialmente en el primer ciclo de aplicación de la institución, poner este porcentaje en función de los costes financieros derivados de la adquisición del suelo, salvo en aquellos casos muy calificados en que proceda la adjudicación gratuita o por precio inferior al coste a tenor de lo dispuesto en el artículo 172, 1, de la Ley del Suelo.

En la redacción de la cláusula tipo que a continuación se propone, en la que el tipo de canon queda en blanco, se prevé la revisión tanto de este tipo como del valor base del terreno. Ambas revisiones parecen necesarias al menos para conseguir, en todo mo- 
mento, uniformidad de trato y evitar con ello desigualdades que pueden ser notorias a lo largo del tiempo.

Cláusula que se propone: I.

«El canon del derecho de superficie ha sido establecido mediante aplicación al valor del suelo de la tasa del "X" por 100. Cada año cuya numeración termine en cero o cinco será revisado el canon mediante revalorización del valor del suelo y adaptación de la tasa al tipo medio de interés ponderado de todas las operaciones financieras en curso que haya contratado la Administración para la adquisición de terrenos con el fin de destinarlos a la constitución del derecho de superficie».

\section{OBRAS DE CONSERVACIÓN Y MEJORA}

Para asegurar en todo caso el mantenimiento de las construcciones en el nivel de conservación y de puesta al día exigible, y ya que no parece que sea ello consustancial a la institución, pues la Ley del Suelo lo silencia, es conveniente que en el título constitutivo la Administración se reserve la facultad de imponer la ejecución de tales obras, tanto más necesaria esa facultad cuanto que la reversión al final del período de las construcciones sin indemnización no estimula ciertamente al superficiario a su espontánea realización. De otra parte, la imposición de mejoras por la Administración puede justificar la indemnización, al menos de éstas, al término de la concesión.

Cláusula que se propone: II.

«El superficiario deberá realizar las obras de conservación y mejora que sean ordenadas por la Administración, bajo sanción, en otro caso, de extinción del derecho».

\section{EXTINCIÓN DEL DERECHO POR TRANSCURSO DE PLAZO}

La Ley del Suelo, en su artículo 173, dispone la extinción del derecho de superficie al transcurrir el plazo, haciendo suyas las edificaciones el cedente y resolviéndose los derechos reales y personales impuestos por el superficiario. Aunque no prohíbe expresamente la Ley la prórroga, parece que tal prohibición está implícita. $\mathrm{Y}$ en todo caso no parece posible que precisamente en el título constitutivo se anuncie la vulneración de la norma del plazo límite de la concesión, admitiendo una eventual prórroga. Además, si el decurso del plazo determina la extinción del derecho, y las 
construcciones, por disposición de la Ley, pasan al dominio del cedente, aunque se admitiese la prórroga de la situación, quedará ésta desprovista de una envoltura jurídica definida.

Frente a este esquema, una evidencia: el caso, no improbable, de construcciones perfectamente utilizables al término del plazo, ocupadas por los propios beneficiarios y en terrenos con destino urbanístico no alterado. Llegada la extinción, resultaría injusto desalojar al superficiario para que ocupase la construcción un tercero en las mismas condiciones, cuando es posible que el superficiario haya tenido buena parte en el estado de conservación que precisamente permite la prolongación del uso.

Atendidas estas razones, se prevé para tales supuestos, que pueden ser numerosos en la práctica, la conversión del derecho del superficiario en arrendamiento, cuyo precio no excederá del canon de superficie, es decir, del valor del terreno.

Parece conveniente esta fórmula no sólo por responder a un criterio de justicia, sino porque hará más sugestiva la institución a los usuarios y supondrá un evidente estímulo para la conservación de las construcciones.

No se extiende el caso al superficiario no ocupante que retiene la construcción sin utilidad social, o que, habiéndola cedido en arrendamiento, a través del precio de éste habrá conseguido lógicamente la total amortización de sus inversiones.

Cuando no procede la transformación del derecho en arrendamiento, se reconoce una indemnización por las mejoras ordenadas por la Administración no amortizadas que no se extiende a los gastos de conservación, pues éstos deben considerarse incluidos en los normales de mantenimiento y dentro de los cálculos de amortización, y porque, en otro caso, quedarían indirectamente estimuladas las construcciones deficientes.

Cláusula que se propone: III.

"Cuando por el transcurso del plazo se extinga el derecho, supuesto que el estado de las construcciones aconseje continuar su utilización y siempre que el destino del suelo no haya sido alterado por los Planes de urbanismo, el superficiario, caso de ser el ocupante del inmueble, tendrá derecho a permanecer en la ocupación, bajo régimen de arrendamiento, con sujeción a la normativa reguladora de dicho contrato y por mientras subsista el doble supuesto previsto al principio de este párrafo. El precio del arrendamiento será igual al canon de superficie, revisable según la cláusula I. 
En otro caso, al momento de extinción, el superficiario tendrá derecho a ser resarcido del valor de las mejoras ordenadas por la Administración, deducida la parte amortizada, a cuyo efecto el plazo de amortización, en anualidades iguales, coincidirá con el plazo por el que hubiese sido concedido el derecho que se extingue».

\section{CESIÓN DEL USO DE LAS CONSTRUCCIONES POR EL SUPERFICIARIO MEDIANTE PRECIO}

Se ha indicado que la modalidad de alquiler es una de las vías que mejor se prestan al desenvolvimiento del derecho de superficie. El sistema parece ser el normal en Suecia y en Austria. Pero en tales casos debe haber un riguroso control de los alquileres. Estos deben estar en función directa del canon de superficie y de la amortización de los costes de construcción, con reconocimiento de un rendimiento a las inversiones realizadas que permita absorber los gastos del inmueble, incluidos los normales de conservación y una lícita ganancia.

Se propone la siguiente cláusula: IV.

«Las construcciones que se realicen en virtud del derecho de superficie otorgado deberán realizarse con arreglo a presupuesto, que será depositado, así como todas sus alteraciones y el de las obras complementarias y de mejora, en la Administración, al que se acompañará la correspondiente tabla de amortización a lo largo del plazo por el que es otorgado el derecho.

Caso de cesión del uso de las construcciones mediante precio, éste no podrá ser superior a la cuota de amortización de las inversiones, más el interés de las mismas, adicionada con el canon de superficie. El interés de las inversiones será igual al tipo que se aplique para el cálculo del canon de superficie incrementado en "X" puntos. El capital pendiente de amortización será revisado cada cinco años con arreglo al índice de desvalorización de la moneda.

La percepción de precios superiores dará lugar a la extinción anticipada del derecho sin indemnización alguna. La no presentación y depósito de los presupuestos dará lugar, en cuanto al coste inicial, a su determinación estimativa por la Administración, con penalización de su 30 por 100, y en cuanto a las obras complementarias y mejoras, a tenerse por no hechas a los efectos previstos en esta cláusula y en la III». 


\section{RESOLUCIÓN POR MODIFICACIÓN DEL PLANEAMIENTO}

Siendo una de las finalidades del derecho de superficie facilitar las operaciones de renovación urbana, es conveniente que, al menos desde el punto de vista jurídico, no haya obstáculos para la posible e inmediata adaptación del suelo a un nuevo planeamiento. El cambio del planeamiento, con alteración del destino del suelo, debe constituir causa de extinción del derecho de superficie, obviamente acompañada del deber de indemnizar.

Se propone la siguiente cláusula: $\mathrm{V}$.

«La alteración del uso urbanístico del suelo como consecuencia. de la modificación de los Planes de ordenación urbana, determinará la resolución del contrato, con la consiguiente extinción del derecho de superficie, correspondiendo al superficiario una indemnización equivalente al valor de las construcciones en la parte pendiente de amortización».

\section{BIBLIOGRAFIA CONSULTADA}

Vicente Guilarte Zapatero: «El derecho de superficie» (Aranzadi, 1966). MIC HEL DESPAX: "Técnicas jurídicas, clásicas y modernas, de utilización del suelo, del subsuelo y del espacio» (RDU, 1968, núm. 6).

José LUIS DE LOS Mozos: «Especulación del suelo y derecho real de superficie urbana» (RDU, 1970, núm. 19).

RAMON MARTfN MATEO: "La penetración pública en la propiedad urbana» (RAP, 1972, núm. 67).

JoSÉ LUIS DE LOS Mozos: "La tecnificación del derecho de superficie y sus posibilidades urbanísticas» (RDU, 1972, núm. 26).

G. MARTY: «El derecho de superficie en relación con la planificación urbana» (RDU, 1972, núm. 27).

José MaRfa CH ICo ORTIZ: "El derecho de propiedad ante la nueva legis. lación urbanística» (RDU, 1973, núm. 33).

ANGel MARTfN DfEZ-QUIJADA: «La cesión de solares por la Administración en régimen de derecho superficiario» (RAP, 1974, núm. 75).

Pfo CARonI: «El derecho de superficie en el Derecho suizo» (RD Privado, abril 1974).

J. P. GILlI: «Redéfinir le droit de propriété» (Centre de Recherche d'Urbanisme, 1975).

Jesús GonZÁlez PÉRez: «Comentarios a la Ley del Suelo» (Civitas, 1976). José LUIS DE Los Mozos: «El derecho de superficie en general y en relación con la planificación urbanística» (Ministerio de la Vivienda. Servicio Central de Publicaciones, 1974). 